\title{
Surface modification of PLGA microspheres
}

\section{Student Paper}

Author(s):

Müller, Markus; Vörös, Janos; Csús, G.; Walter, E.; Danuser, Gaudenz; Textor, Marcus; Spencer, N.D.

Publication date:

2001

Permanent link:

https://doi.org/10.3929/ethz-a-004312432

Rights / license:

In Copyright - Non-Commercial Use Permitted 


\section{Surface Modification of PLGA Microspheres}

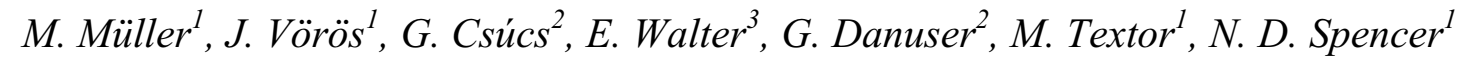

${ }^{1}$ Laboratory for Surface Science and Technology, Department of Materials, Swiss Federal Institute of Technology, ETH-Zürich, Switzerland.

${ }^{2}$ Laboratory for Biomicrometries, Department of Mechanical and Process Engineering, Swiss Federal Institute of Technology, ETH-Zürich, Switzerland.

${ }^{3}$ Institute of Pharmaceutical Science and Technology, Swiss Federal Institute of Technology, ETH Zürich, Switzerland. 


\section{Abstract}

Microspheres made of poly(lactic-co-glycolic acid) (PLGA) are fully biocompatible and biodegradable which renders PLGA microspheres a promising tool in the context of drug delivery. However the adsorption of plasma proteins on micro- and nanospheres is a main limitation of drug targeting. Poly(L-lysine)-g-poly(ethylene glycol) (PLL-g-PEG), physisorbed on flat metal oxide surfaces, has previously been shown to drastically suppress protein adsorption. The goal of the present work was to characterize the efficiency of the protein repellent character of PLL- $g$-PEG on PLGA microspheres and to show the feasibility of introducing functional groups on the PLGA microspheres via functionalized PLL-g-PEG.

To quantify the adsorbed amount of protein a semi-quantitative method, which uses confocal laser scanning microscopy (CLSM), was applied.

The first part of the experiment confirms the feasibility of introducing specific functional groups on PLL-g-PEG coated PLGA microspheres. In the second part of the experiment PLL- $g$-PEG coated PLGA microspheres show a drastic decrease of adsorbed proteins by two orders of magnitude in comparison to uncoated PLGA microspheres.

Low protein binding functionalizable microspheres provide a fundamental basis for the design of drug delivery and biosensor systems.

\section{Introduction}

Colloidal carriers such as micro- and nanospheres are regarded as a promising approach for drug targeting to specific organs of the body in order to reduce drug side effects and to permit a sustained release at the target site [1]. Microspheres made of poly(lactic-co-glycolic acid) (PLGA) are fully biocompatible and biodegradable [2-4], a prerequisite in drug delivery. This is the reason why PLGA is the most commonly used and investigated material for the microencapsulation of therapeutics at present. A serious handicap in drug targeting is the rapid uptake of intravenously injected particulate drug carriers by the cells of the reticuloendothelial system (RES), comprising mainly the Kupffer cells of the liver and the macrophages of the spleen and bone marrow [5]. The filtration mechanism of the spleen also plays an important role in the clearance of colloidal particles [6]. Hence the circulation time of PLGA microspheres in a blood stream in vivo is determined by the physicochemical characteristics of the particles especially their size, surface charge and surface affinity [7]. It has long been known that the removal of particles by the spleen increases with increasing particle size [6]. The adsorption of plasma proteins on the other hand is regarded as the key factor in explaining the organ distribution of microspheres. The presence of specific proteins 
(opsonins), e.g., $\gamma$-immunoglobulin G (IgG), is known to promote the ingestion by cells of the RES by either specific or non-specific interactions with cell membrane receptors [8]. Therefore not only the total bound protein but also the presence of opsonins and their conformation are expected to influence macrophage uptake. It is also reported that there may be a minimum concentration for certain proteins required to cause an effect, and proteins present in minute amounts are unlikely to be of importance [8].

Several approaches to reduce the protein adsorption on colloid carriers were investigated and published. The plasma protein adsorption on microspheres made of ABA triblock copolymers containing poly(ethylene glycol) (PEG) was reduced by 5 to 7 times compared to microspheres made of pure polyesters [9]. The modification of PLGA particles with PEG is another important and wellknown approach to reduce protein adsorption. Gref et al. [10] investigated the influence of the molecular weight and surface density of PEG chains on competitive plasma protein adsorption. A maximal reduction in protein adsorption by a factor of 4 to 5 was achieved under optimized conditions. Poloxamer and poloxamine series adsorbed on polystyrene (PS) particles build a PEGrich hydrophilic steric barrier that causes a decrease of serum proteins by about 5 times at a $0.3 \%$ $(\mathrm{v} / \mathrm{v})$ serum concentration. However, at a serum concentration of $50 \%(\mathrm{v} / \mathrm{v})$ an increase of protein adsorption on coated particles in comparison to uncoated particles was found [11]. Further Harper et al. reported a considerable reduction in the uptake of PEG grafted PS particles by the Kupffer cells compared to naked latex particles [12].

In the present work we focused on the polymer system poly(L-lysine)-g-poly(ethylene glycol) (PLLg-PEG) (Figure 1), which is known from earlier investigations, performed on flat metal oxide surfaces, to drastically reduce protein adsorption [13,14]. PLL-g-PEG consists of a poly(L-lysine) (PLL) backbone, which is highly cationic at a physiological $\mathrm{pH}$ [14] and interacts with the negatively charged PLGA microsphere surface by electrostatic forces. The PLL backbone is grafted with PEG chains, which exhibit the protein-resistant performance. PEG has been extensively investigated for use in a wide array of biomedical applications, and immobilization of PEG on surfaces has long been known to decrease protein adsorption. The protein-suppression performance was found to depend on the molecular weight of PEG, the grafting ratio in the PLL-g-PEG copolymer, and the surface coverage of the polymer[10,13]. Graft copolymers of PLL and PEG have been evaluated in the context of drug delivery for toxicity [15], immunogenicity, immunomodulatory potential, pyrogenicity and biodegradation [16-18], all of which suggest that PLL-g-PEG polymer coatings on PLGA microspheres could be a promising approach for drug delivery.

In the present study we focused on characterizing the efficiency of the protein-repellent character of PLL-g-PEG on PLGA microspheres and on showing the feasibility of introducing functional groups on the PLGA microspheres via modified PLL-g-PEG. Microspheres made of PLGA were prepared 
by a spray-dry process and characterized in terms of size distribution and $\zeta$-potential. To investigate the adsorbed amount of proteins a semi-quantitative method using confocal laser scanning microscopy (CSLM) was applied.

\section{Materials and Methods}

\subsection{Preparation and Characterization of Microspheres}

Poly(lactic-co-glycolic acid) (PLGA : type RG $502 \mathrm{H}$, Boehringer Ingelheim, Germany) microspheres were prepared by a spray-dry method $[19,20]$ using dichloromethane as the solvent. The parameters of the spray-dry process were as follows: $45^{\circ} \mathrm{C}$ air temperature; $600 \mathrm{Nl} / \mathrm{h}$ air flow and $3 \mathrm{~mL} / \mathrm{min}$ pump control. The microparticles were washed with water, collected on a $0.45 \mu \mathrm{m}$ cellulose acetate membrane filter and subsequently dried under vacuum for 24 hours.

The size and size distribution of the microspheres were determined using low angle laser light scattering (LALLS) (Malvern Instruments Ltd., UK). Calculation of particle size was based on Mie's theory accounting for the optical properties of the polymer [21]. In order to inhibit agglomeration, the microspheres were dispersed in Tween 20 during the measurements. Zeta potential measurements were carried out in phosphate buffer at $\mathrm{pH} 7.4$ (ionic strength $=0.01$ ) by using a ZETA-Meter System 3+ (ZM3+ 331, Zeta-Meter, Inc., USA).

\subsubsection{Coating PLGA Microspheres with Polymer Mixtures}

A low ionic strength buffer HEPES I (10mM N-2-hydroxypiperazine-N-3-propanesulfonic acid (HEPES) with an adjusted pH of 7.4) was chosen to enhance the electrostatic interaction between the positively charged PLL- $g$-PEG and the negatively charged surface of the PLGA microspheres.

Different mixtures of PLL-g-PEG and PLL-g-PEG/PEGbiotin were prepared in HEPES I with $1 \mathrm{mg} / \mathrm{mL}$ total polymer concentration. The molecular weight of the PLL backbone and PEG side chains were $20 \mathrm{kDa}$ and $2 \mathrm{kDa}$ respectively. The molecular weight of the biotinilated PEG side chains was $3.5 \mathrm{kDa}$. The grafting ratio of lysine units/PEG side chains was 3.3 and the percentage of biotinylated PEG chains of PLL- $g$-PEG/PEGbiotin was 31\%. Figure 1 and 2 show the chemical structures of PLL-g-PEG and PLL-g-PEG/PEGbiotin respectively.

10 different mixtures of PLL- $g$-PEG and PLL- $g$-PEG/PEGbiotin were prepared such that in the mixture the ratio of biotinilated PEG chains versus unfunctionalized PEG chains varied between 0 and $31 \%$. $0.1 \mathrm{~mL}$ of the appropriate mixture was added to $0.1 \mathrm{~mL}$ PLGA microspheres. Both the polymer and the microspheres had a concentration of $1 \mathrm{mg} / \mathrm{mL}$ in HEPES I. After 10 minutes of incubation the solution was centrifuged (Minispin, Eppendorf, Switzerland) at $87300 \mathrm{~g}$ for 13 
minutes. Then the supernatant was carefully removed, and the microspheres were dispersed in $0.1 \mathrm{~mL}$ HEPES I by stirring the solution using a pipette and subsequent vortexing. (These centrifugation parameters and this dispersion method were used in all of the experiments and will be referred to as centrifugation and redispersion, respectively, from now on in the text.)

$0.1 \mathrm{ml}$ of $0.04 \mathrm{mg} / \mathrm{mL}$ fluorescently labeled streptavidin, Oregon Green 488 conjugate (Molecular Probes, USA) solution in HEPES I was added. After 45 minutes of incubation in darkness the solution was centrifuged and redispersed in $0.2 \mathrm{~mL}$ HEPES I. For the final concentrations see Table 1 and for the coating process see the schematic in Figure 3.

\subsubsection{Protein Adsorption on PLGA Microspheres}

Representatives of human proteins: human serum albumin (HSA), fibrinogen (Fb), fibronectin (Fn), $\gamma$-immunoglobulin G (IgG) (Sigma-Aldrich, USA) were used to test the protein resistance of the PLL-g-PEG-coated PLGA microspheres. A buffer with close to physiological ionic strength, HEPES II (10 mM HEPES with $150 \mathrm{mM} / \mathrm{L} \mathrm{NaCl}, \mathrm{pH}$ 7.4) was used in these experiments. $0.1 \mathrm{~mL}$ of the appropriate protein at a concentration of $0.2 \mathrm{mg} / \mathrm{mL}$ in HEPES II was added to $0.1 \mathrm{~mL}$ of PLL$g$-PEG-coated (see previous section) or uncoated PLGA microspheres (used as a reference) which were predispersed in HEPES II at a concentration of $1 \mathrm{mg} / \mathrm{mL}$. After an incubation time of 45 minutes the solution was centrifuged and the microspheres were redispersed in 0.1 mL HEPES II. $0.08 \mathrm{mg} / \mathrm{mL}$ of the corresponding primary antibody in $0.1 \mathrm{~mL}$ HEPES II was added. All primary antibodies against the human proteins were polyclonal antibodies raised in rabbit obtained from DAKO (Switzerland). After 45 minutes of incubation the centrifugation and redispersion steps were repeated. Fluorescently labeled secondary antibody (goat anti-rabbit IgG Oregon Green 488 conjugate, Molecular Probe, USA) at a concentration of $0.08 \mathrm{mg} / \mathrm{mL}$ in $0.1 \mathrm{~mL}$ HEPES II was added to the microsphere dispersion and incubated in darkness for 45 minutes. After centrifugation the microspheres were redispersed in 0.2 mL HEPES II and immediately measured by CLSM. Table 1 gives a summary of the used concentrations, and the coating process is illustrated in Figure 4.

\subsubsection{Cross-Test}

In order to test the specificity of the antibody technique one cross-test was performed.

PLL-g-PEG coated and uncoated microspheres were exposed to one of the proteins mentioned earlier in 3.1.2, then to a non-corresponding primary antibody and finally to the fluorescently labeled secondary antibody. The coating process was performed as explained in detail in section 3.1.2 


\subsection{Quantification of Adsorbed Proteins}

A semi-quantification of the adsorbed amount of proteins was performed by measuring the fluorescent signal of the secondary antibody labeling on the surface of the microspheres. The labeled microspheres were let to sediment on a coverslip and cross-sectional images were taken from several microspheres at different heights by using a confocal laser scanning microscope (Figure 5a). The fluorescence intensity (measured in arbitrary units) of the microsphere surfaces was determined as follows: The recorded cross-sectional images were projected onto one plane and the total (integrated) fluorescence intensity was divided by the number of images in one stack (20 images) (Figure 5b). To obtain statistically relevant data this procedure was applied to ten arbitrarily chosen microspheres. In our experiments we used a Zeiss 510 confocal microscope equipped with a $63 \mathrm{x} 1.25 \mathrm{NA}$ PlanNeofluar objective. For excitations of the fluorophore we used the $488 \mathrm{~nm}$ line of an Ar laser. In all experiments the laser power was minimized in order to avoid photobleaching. At each measurement we collected 20 cross sectional images in $500 \mathrm{~nm}$ intervals defining the mid plane of the stack at the highest cross sectional diameter of the microsphere.

To assess the absolute amount of adsorbed proteins on the microsphere surface a calibration measurement with an independent quantitative technique (e.g., optical waveguide light mode spectroscopy or radio labeling) is needed.

\section{Results and Discussion}

\subsection{Characterization of Microspheres}

PLGA microspheres were analyzed by LALLS for their size distribution. The distribution of the diameter of the PLGA microspheres ranges from approximately $0.1 \mu \mathrm{m}$ to $10 \mu \mathrm{m}$. Because of the limited resolution of the light microscope only microspheres with diameters above $1 \mu \mathrm{m}$ were examined.

PLGA microspheres displayed a strongly negative zeta potential of $-65.9 \pm 11.2 \mathrm{mV}$.

\subsection{Functionalized PLGA Microspheres}

In this experiment the feasibility of functionalizing PLGA microspheres was investigated. Mixtures of PLL- $g$-PEG and PLL-g-PEG/PEGbiotin, with ratios of biotinilated PEG side chains versus unfunctionalized PEG side chains varying between 0 and $31 \%$, were used as a model system. The specificity of the coating was tested with streptavidin Oregon-Green conjugate. Sample preparation was carried out as described in section 3.1.1 
Figure 6 shows a linear dependence between the amount of bound streptavidin Oregon-Green conjugate and the proportion of biotinilated side chains in the polymer mixture. These findings agree very well with results form earlier work where the adsorbed amount of streptavidin on biotinylated PLL-g-PEG-coated metal oxide surfaces was quantified using an optical waveguide technique [22]. This correlation confirms the feasibility of introducing functional groups to PLL- $g$-PEG-coated PLGA microspheres while preserving the full biological functionality of the biotin-streptavidin system. The possibility to produce functionalized protein-repellent microsphere surfaces is crucial for drug targeting. Therefore further functionalizing experiments with peptides as functional group will be performed to achieve the specificity required for drug targeting.

The linear dependence of the measured fluorescent intensity, emitted by the streptavidin OregonGreen conjugate, on the concentration of biotin indicates that it is feasible to use the fluorescence microscopy method to determine the amount of adsorbed proteins on the microspheres.

\subsection{Adsorption and Protein-Resistance Study}

In this experiment PLL- $g$-PEG-coated and uncoated PLGA microspheres were exposed to representatives of human serum proteins to test the efficiency of protein repulsion. See section 3.1.2 for a description of the sample preparation and coating process.

PLL-g-PEG coated PLGA microspheres showed a decrease of adsorbed proteins by two orders of magnitude in comparison to uncoated PLGA microspheres (see Table 2). All the observed particles showed a homogenous distribution of proteins to within the limits of resolution of CLSM.

The result of this experiment confirms that the well-known protein repellent character of PLL- $g$ PEG, investigated on flat metal oxide surfaces in earlier work $[13,14]$ is transferable to PLL-g-PEG coated PLGA microspheres.

The control experiment, in which the non-corresponding primary antibody was added after protein adsorption, showed a decrease in the fluorescence intensity by two order of magnitudes for PLL- $g$ PEG-coated and uncoated microspheres comparable to the fluorescence intensity of uncoated microspheres which were exposed to the corresponding primary antibody after protein exposure. Hence the non-specific binding of the antibodies is negligible. The high specificity of the corresponding antibody indicates that the epitopes of the adsorbed proteins are still recognizable for the antibodies. 


\section{Summary and Conclusions}

PLL-g-PEG-coated flat model metal oxide surfaces were widely examined in earlier work [13,14] and have been found to display drastically reduced protein adsorption relative to unmodified metal oxide surfaces. As a next step in the direction of future development in the areas of drug targeting and biosensing, we verified in this work the feasibility of generating protein-repellent biodegradable PLGA microspheres by coating them with PLL-g-PEG.

A sharp decline of protein adsorption on PLL- $g$-PEG coated PLGA microspheres was observed for all tested proteins (HSA, Fb, Fn and IgG). Furthermore we could show that it is feasible to introduce functional groups such as biotin to PLL-g-PEG-coated PLGA microspheres. Low protein binding functionalizable microspheres provide a fundamental basis for the design of drug-delivery and biosensor systems.

\section{Acknowledgment}

The authors thanks Susan De Paul for their continuos support and valuable comments.

1. Putney S D (1998) Encapsulation of proteins for improved delivery. Current Opinion in Chemical Biology 2 ( 4 ): 548-552

2. Athanasiou K A, Niederauer G G, Agrawal C M (1996) Sterilization, toxicity, biocompatibility and clinical applications of polylactic acid polyglycolic acid copolymers. Biomaterials 17 ( 2 ): 93-102

3. Tracy M A, Ward K L, Firouzabadian L, Wang Y, Dong N, Qian R, Zhang Y (1999) Factors affecting the degradation rate of poly(lactide-co- glycolide) microspheres in vivo and in vitro. Biomaterials 20 ( 11 ): 1057-1062

4. Visscher G E, Robison R L, Maulding H V, Fong J W, Pearson J E, Argentieri G J (1985) Biodegradation of and Tissue Reaction to 50-50 Poly(D1-Lactide- Co-Glycolide) Microcapsules. Journal of Biomedical Materials Research 19 ( 3 ): 349-365

5. Moghimi S M, Patel H M (1989) Differential Properties of Organ-Specific Serum Opsonins for Liver and Spleen Macrophages. Biochimica Et Biophysica Acta 984 ( 3 ): 379-383

6. Moghimi S M, Porter C J H, Muir I S, Illum L, Davis S S (1991) Non-Phagocytic Uptake of Intravenously Injected Microspheres in Rat Spleen - Influence of Particle-Size and Hydrophilic Coating. Biochemical and Biophysical Research Communications 177 ( 2 ): $861-866$ 
7. Illum L, Jacobsen L O, Muller R H, Mak E, Davis S S (1987) Surface Characteristics and the Interaction of Colloidal Particles with Mouse Peritoneal-Macrophages. Biomaterials 8 ( 2 ): $113-117$

8. Blunk T, Hochstrasser D F, Sanchez J C, Muller B W, Muller R H (1993) Colloidal Carriers for Intravenous Drug Targeting - Plasma- Protein Adsorption Patterns on SurfaceModified Latex-Particles Evaluated by 2-Dimensional Polyacrylamide-Gel Electrophoresis. Electrophoresis 14 ( 12 ): 1382-1387

9. Luck M, Pistel K F, Li Y X, Blunk T, Muller R H, Kissel T (1998) Plasma protein adsorption on biodegradable microspheres consisting of poly(D,L-lactide-co-glycolide), poly(L-lactide) or ABA triblock copolymers containing poly(oxyethylene) - Influence of production method and polymer composition. Journal of Controlled Release 55 ( 2-3 ): 107120

10. Gref R, Luck M, Quellec P, Marchand M, Dellacherie E, Harnisch S, Blunk T, Muller R H (2000) 'Stealth' corona-core nanoparticles surface modified by polyethylene glycol (PEG): influences of the corona (PEG chain length and surface density) and of the core composition on phagocytic uptake and plasma protein adsorption. Colloids and Surfaces BBiointerfaces 18 ( 3-4 ): 301-313

11. Norman M E, Williams P, Illum L (1993) Influence of Block Copolymers on the Adsorption of Plasma- Proteins to Microspheres. Biomaterials 14 ( 3 ): 193-202

12. Harper G R, Davies M C, Davis S S, Tadros T F, Taylor D C, Irving M P, Waters J A (1991) Steric Stabilization of Microspheres with Grafted Polyethylene Oxide Reduces Phagocytosis by Rat Kupffer Cells-Invitro. Biomaterials 12 ( 7 ): 695-704

13. Huang N P, Michel R, Voros J, Textor M, Hofer R, Rossi A, Elbert D L, Hubbell J A, Spencer N D (2001) Poly(L-lysine)-g-poly(ethylene glycol) layers on metal oxide surfaces: Surface-analytical characterization and resistance to serum and fibrinogen adsorption. Langmuir 17 ( 2 ): 489-498

14. Kenausis G L, Voros J, Elbert D L, Huang N P, Hofer R, Ruiz-Taylor L, Textor M, Hubbell J A, Spencer N D (2000) Poly(L-lysine)-g-poly(ethylene glycol) layers on metal oxide surfaces: Attachment mechanism and effects of polymer architecture on resistance to protein adsorption. Journal of Physical Chemistry B 104 ( 14 ): 3298-3309

15. Elbert D L, Hubbell J A (1998) Self-assembly and steric stabilization at heterogeneous, biological surfaces using adsorbing block copolymers. Chemistry \& Biology 5 ( 3 ): 177183 
16. Bogdanov a A, Weissleder R, Frank H W, Bogdanova a V, Nossif N, Schaffer B K, Tsai E, Papisov M I, Brady T J (1993) A New Macromolecule as a Contrast Agent for MrAngiography - Preparation, Properties, and Animal Studies. Radiology 187 ( 3 ): 701-706

17. Bogdanov a A, Martin C, Bogdanova a V, Brady T J, Weissleder R (1996) An adduct of cis-diamminedichloroplatinum(II) and poly(ethylene glycol)poly(L-lysine)-succinate: Synthesis and cytotoxic properties. Bioconjugate Chem. 7: 144-149

18. Ryser H J P, Mandel R, Hacobian A, Shen W C (1988) Methotrexate-Poly(Lysine) as a Selective Agent for Mutants of Chinese-Hamster Ovary Cells Defective in Endocytosis. Journal of Cellular Physiology 135 ( 2 ): 277-284

19. Gander B, Wehrli E, Alder R, Merkle H P (1995) Quality Improvement of Spray-Dried, Protein-Loaded D,L-Pla Microspheres by Appropriate Polymer-Solvent Selection. Journal of Microencapsulation 12 ( 1 ): 83-97

20. Walter E, Moelling K, Pavlovic J, Merkle H P (1999) Microencapsulation of DNA using poly(DL-lactide-co-glycolide): stability issues and release characteristics. Journal of Controlled Release 61 ( 3 ): 361-374

21. Thomasin C, Corradin G, Men Y, Merkle H P, Gander B (1996) Tetanus toxoid and synthetic malaria antigen containing poly(lactide)/poly(lactide-co-glycolide) microspheres: Importance of polymer degradation and antigen release for immune response. Journal of Controlled Release 41 ( 1-2 ): 131-145

22. Huang N P, Vörös J, De Paul S D, Textor M, Spencer N D (2001) Biotin-Derivatized Poly(L-lysine))-g-Poly(ethylene glycol): A Novel Polymeric Interface for Bioaffinity Sensing. Submitted to Langmuir: 


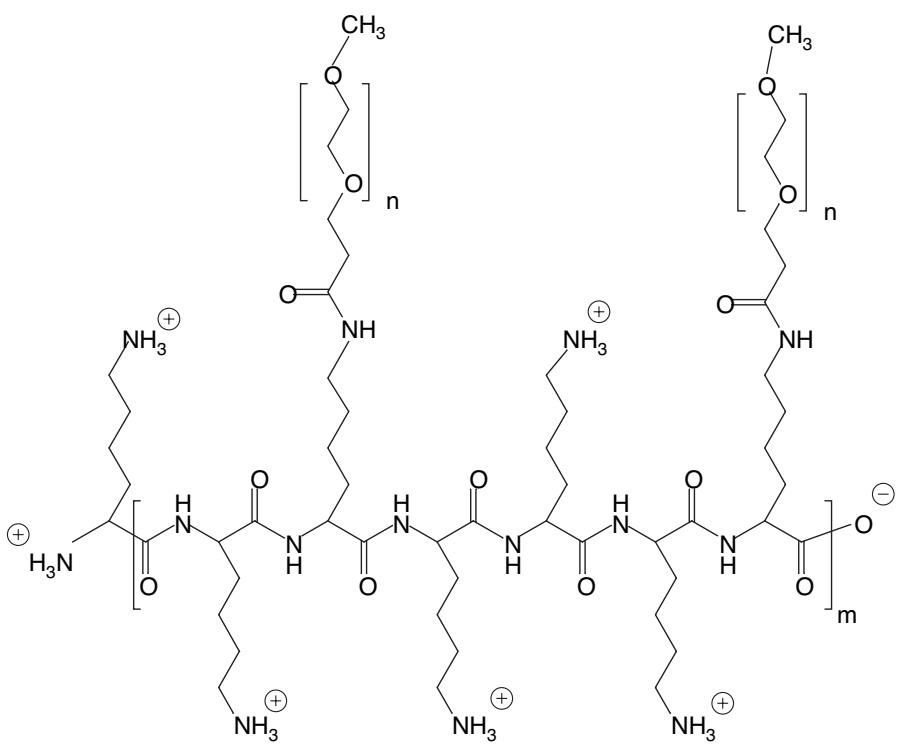

Figure 1: Chemical structure of PLL-g-PEG. PLL-g-PEG consists of a PEG grafted PLL backbone which is positively charged at a $\mathrm{pH}$ of 7.4. The molecular weight of the PLL and PEG were $20 \mathrm{kDa}$ and $2 \mathrm{kDa}$ respectively and the grafting ratio of lysine units/PEG side chains was 3.3.

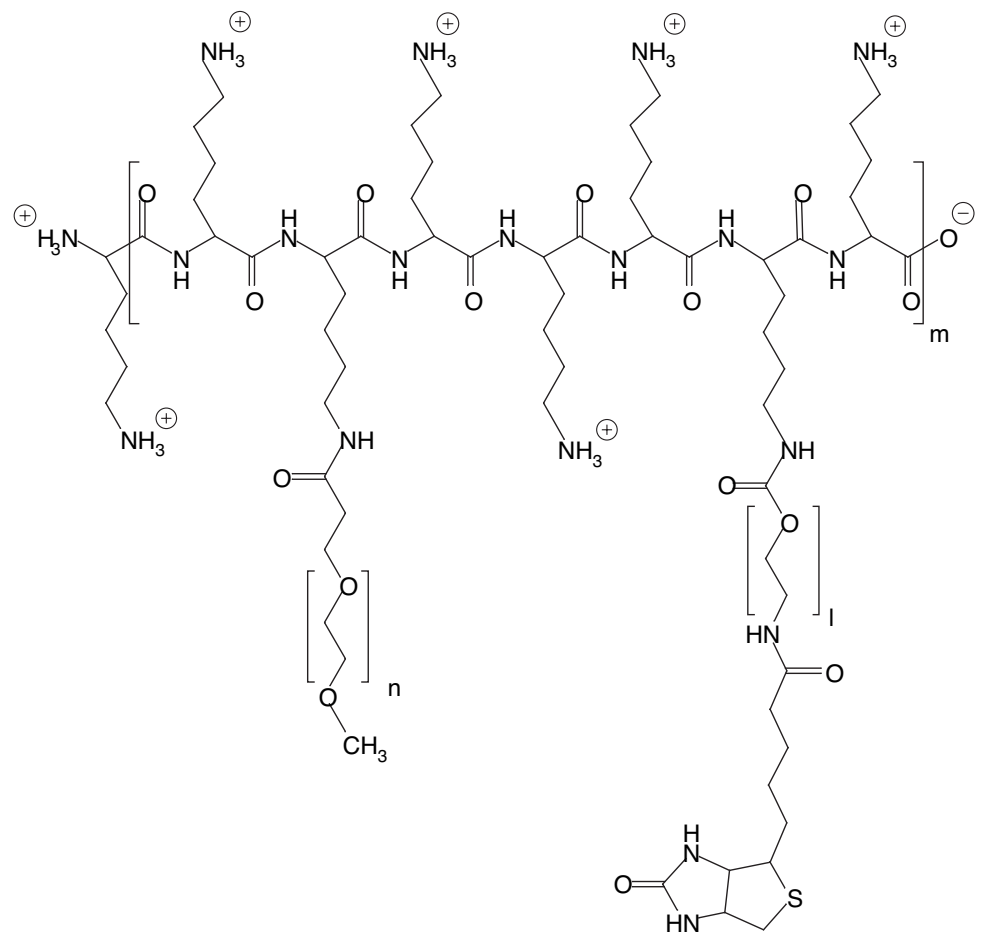

Figure 2: Chemical structure of PLL-g-PEG/PEGbiotin. Biotin is covalently bound to $31 \%$ of PEG side chains. Molecular weight and grafting ratio were equal to the unfunctionalized PLL-g-PEG except for the molecular weight of PEGbiotin side chains which was $3.5 \mathrm{kDa}$. 

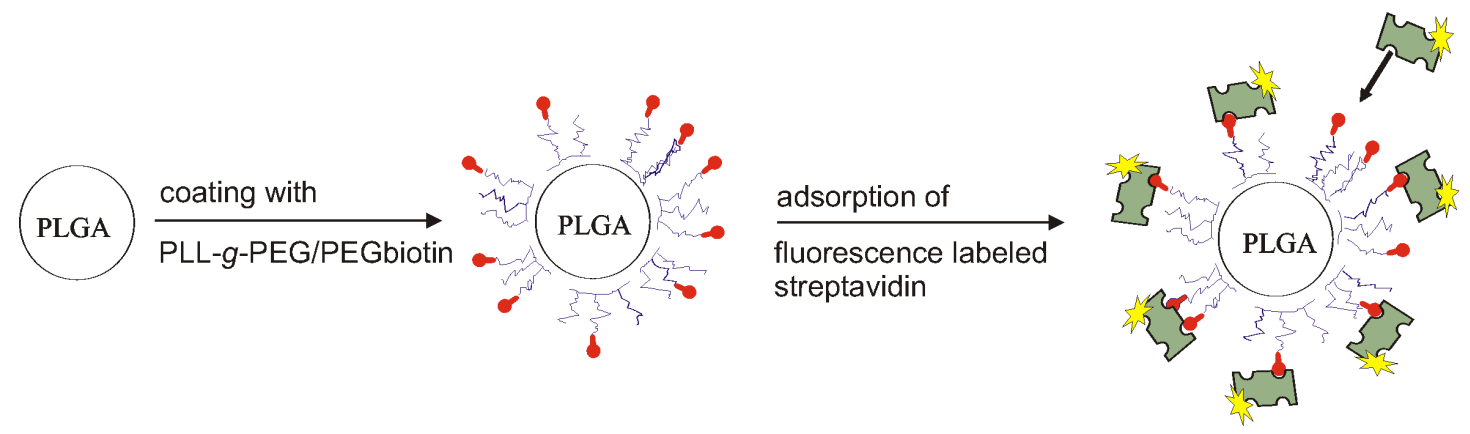

Figure 3: Coating process of PLGA-microspheres with a polymer mixture of PLL-gPEG/PEGbiotin with 0 to $31 \%$ of the PEG chains containing biotin. The specificity of the coating was tested with Oregon-Green labeled streptavidin.

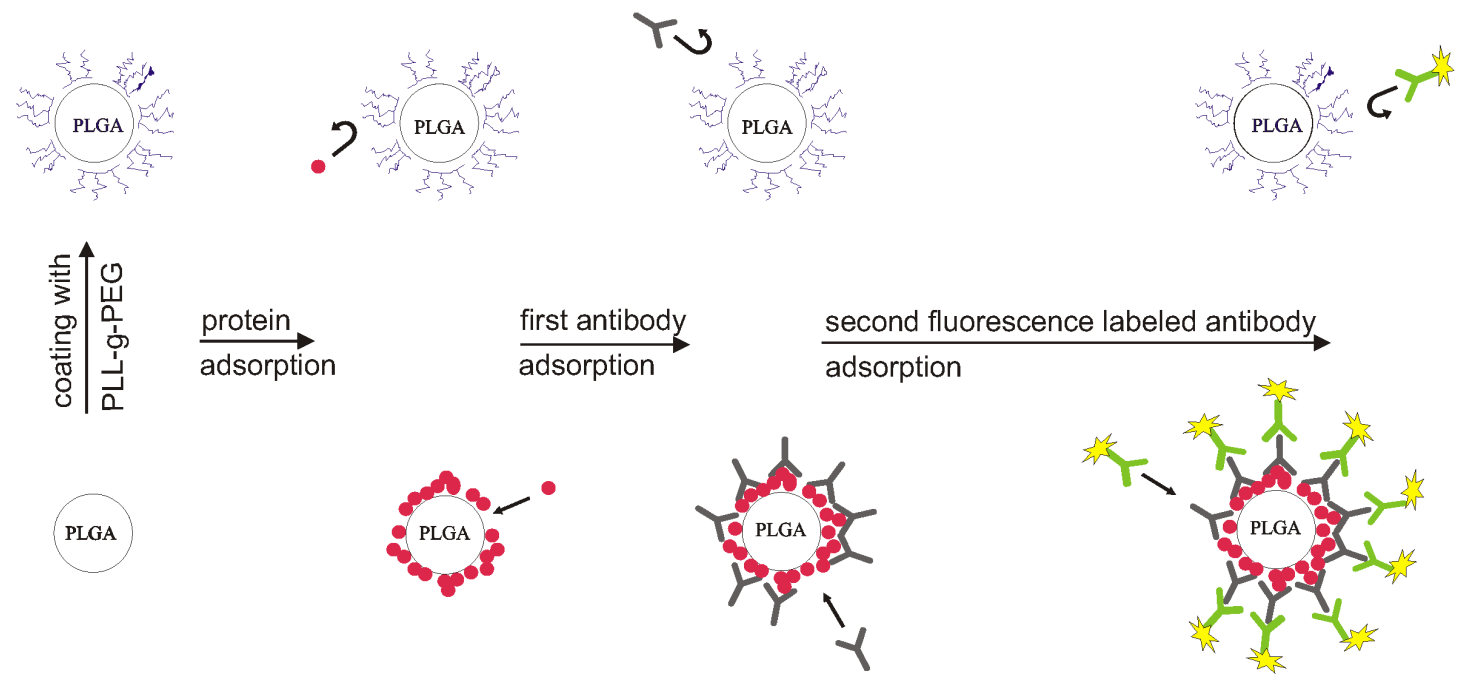

Figure 4: Schematic of the coating process of PLGA microspheres. Coated and uncoated PLGA microspheres (used as a reference) were exposed to representative human proteins and their corresponding antibodies and finally to a secondary antibody which was fluorescently labeled. 
a)

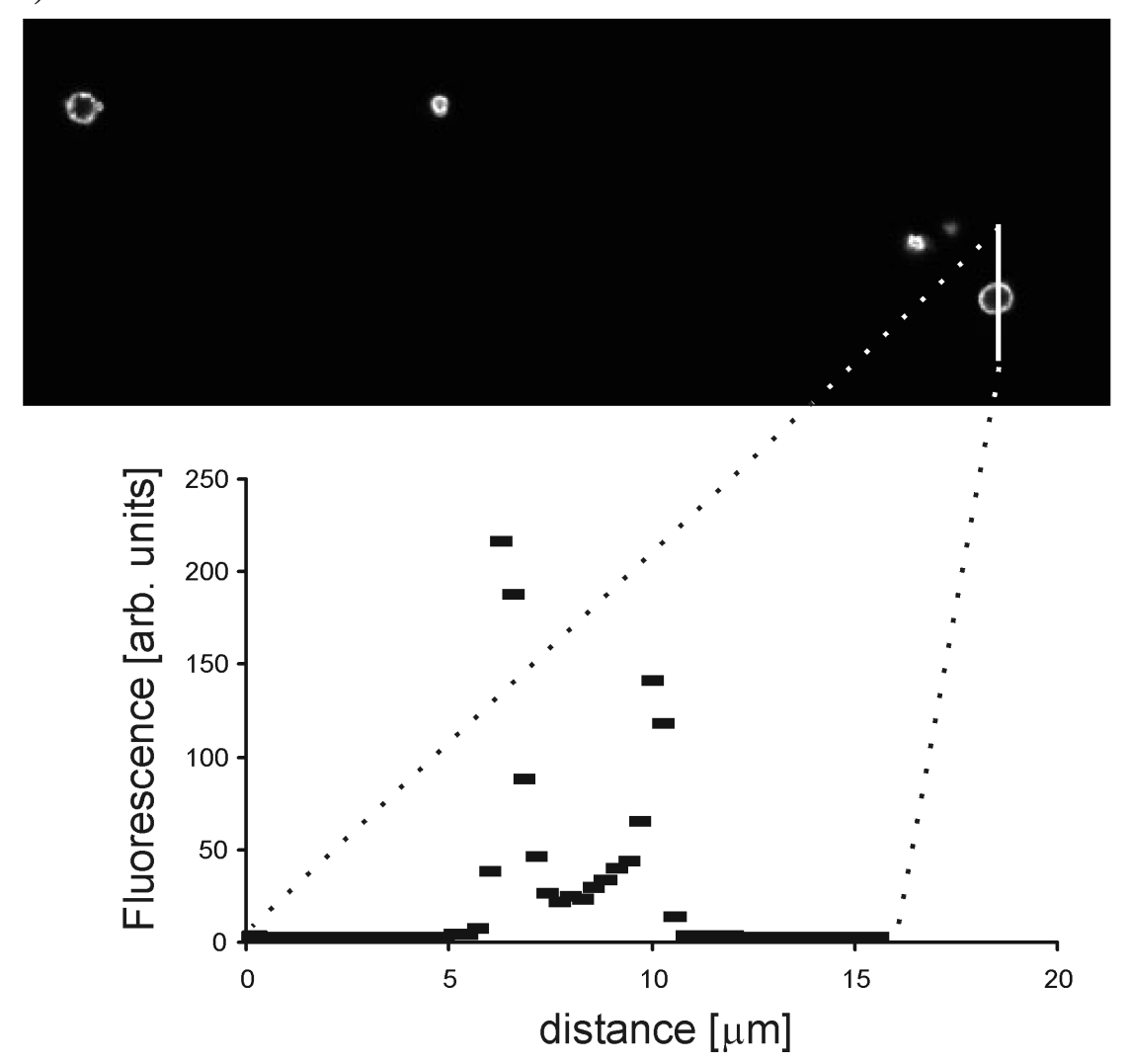

b)

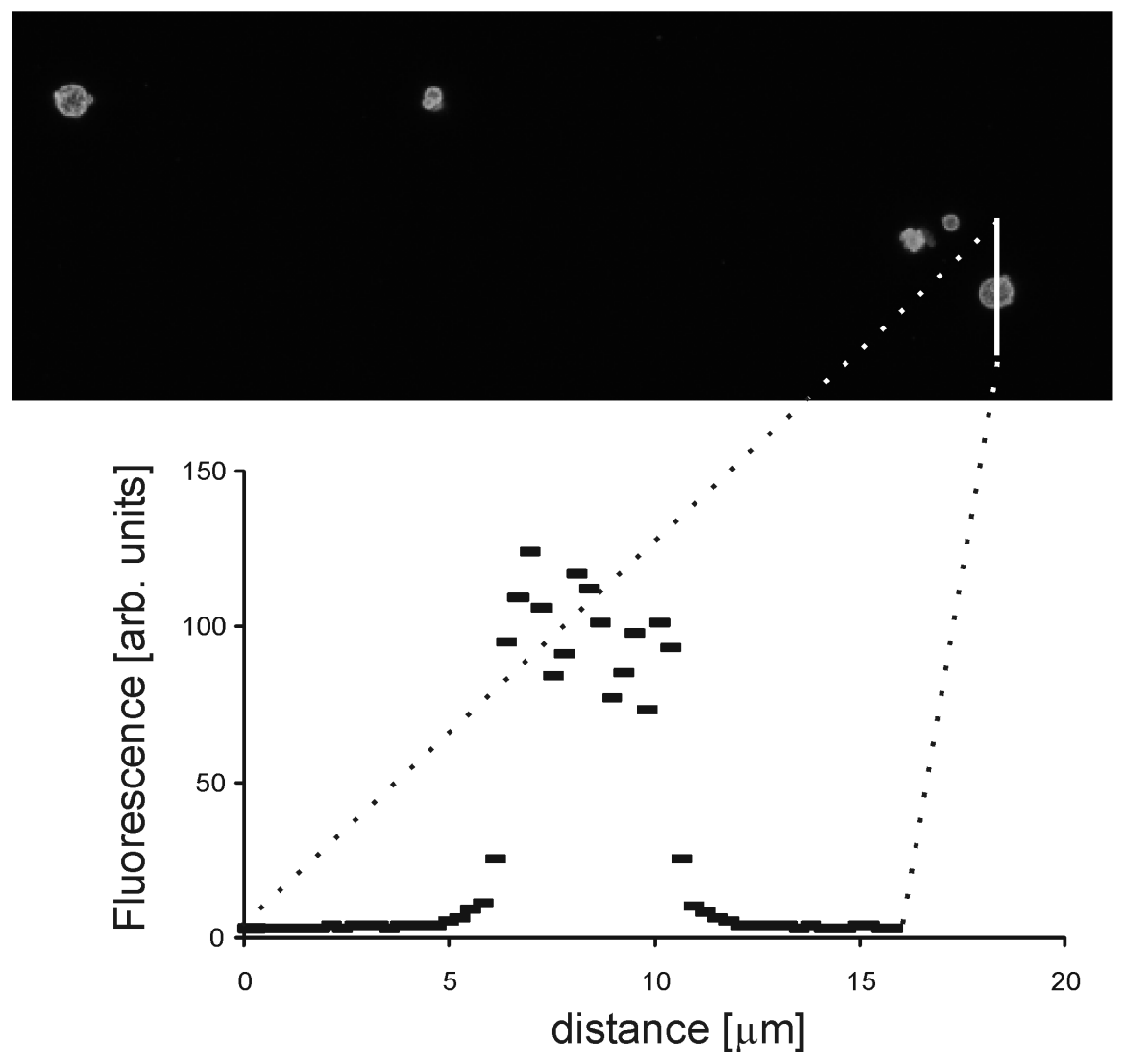


Figure 5: Confocal laser scanning microscope images of the microspheres.

a) Cross-sectional images of several microspheres and the corresponding fluorescence intensities.

b) Recorded cross-sectional images are projected onto one plane and the total fluorescence intensity (measured in arbitrary units) divided by the number of images in one stack was used for the quantification of the adsorbed amount of proteins on the microsphere surface.

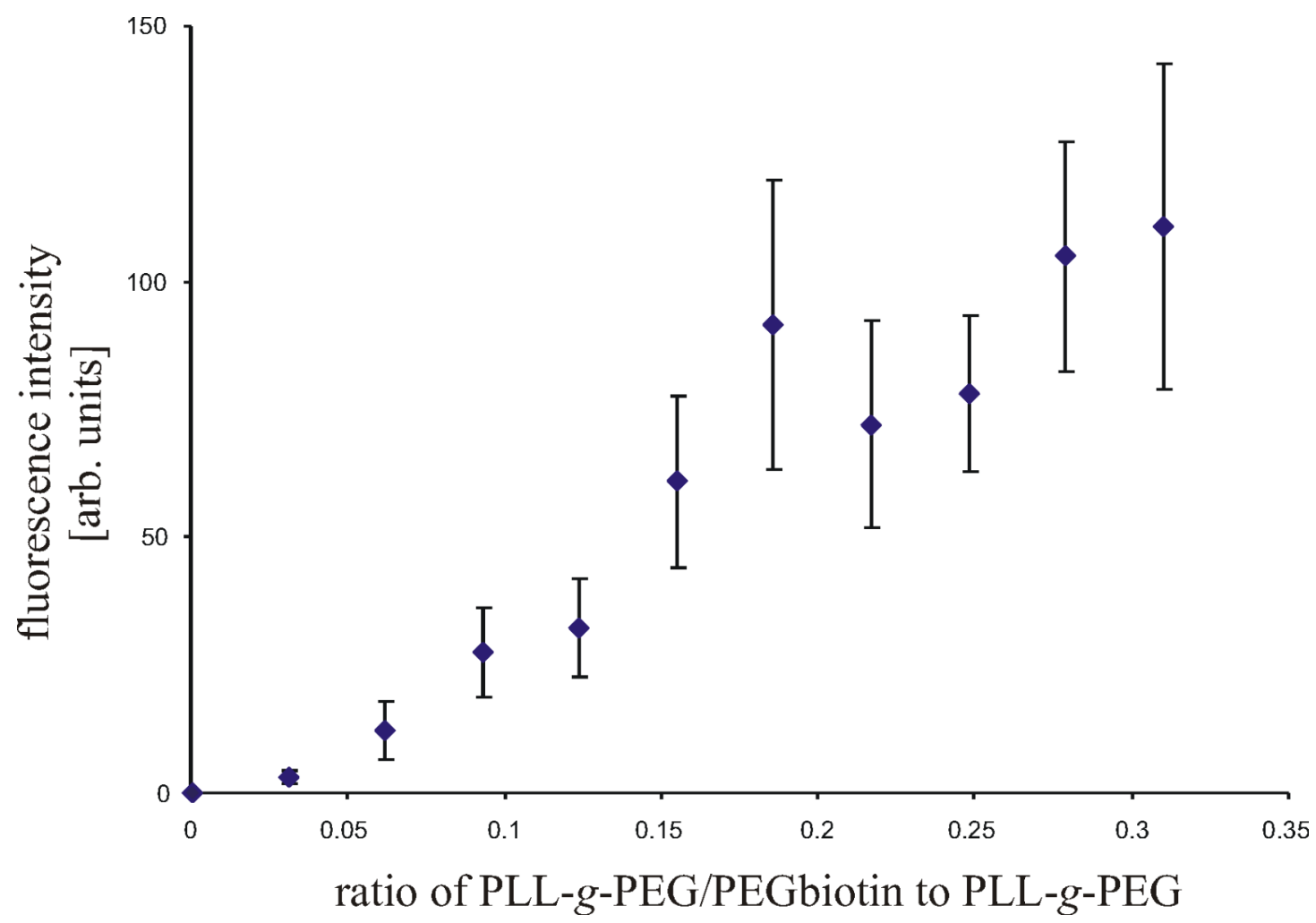

Figure 6: Fluorescence intensity of bound labeled streptavidin on the surface of the microspheres as a function of the ratio of PLL-g-PEG/PEGbiotin to PLL-g-PEG in the coating solution. 


\begin{tabular}{l|c} 
Materials & $\begin{array}{c}\text { Final concentration } \\
{[\mathbf{m g} / \mathbf{m L}]}\end{array}$ \\
\hline PLGA microspheres & 0.5 \\
\hline Polymer mixture of PLL-g-PEG & 1 \\
and PLL-g-PEG/PEGbiotin & 0.1 \\
\hline HSA & 0.1 \\
Fibrinogen & 0.1 \\
Fibronectin & 0.1 \\
IgG & 0.04 \\
Primary antibody & 0.04
\end{tabular}

Table 1: Survey of final concentrations of the coating experiments.

\begin{tabular}{l|c|c} 
Proteins & $\begin{array}{c}\text { Microspheres uncoated } \\
\text { Fluorescence intensity } \\
\text { [arb. Units] }\end{array}$ & $\begin{array}{c}\text { Microspheres PLL-g-PEG coated } \\
\text { Fluorescence intensity } \\
\text { [arb. Units] }\end{array}$ \\
\hline HSA & $27 \pm 40$ & $0.16 \pm 0.22$ \\
Fibrinogen & $63 \pm 47$ & $0.15 \pm 0.19$ \\
Fibronectin & $4.1 \pm 3.1$ & $0.03 \pm 0.04$ \\
IgG & $42 \pm 33$ & $0.25 \pm 0.22$
\end{tabular}

Table 2: Quantification of the amount of proteins adsorbed on PLL-g-PEG coated and uncoated microspheres as measured by CLSM using secondary antibody technique.

The fluorescence intensity is expressed in arbitrary units. The values are the means of three experiments. 